\title{
Demorgaphy of the Tribal Groups of Rajasthan: 4. Selection Intensity
}

\author{
M.K. Bhasin and Shampa Nag \\ Department of Anthropology, University of Delhi, Delhi 110 007, India
}

KEYWORDS Tribes. Rajasthan. Fertility. Mortality. Selection Intensity

\begin{abstract}
Natural selection is one of the major evolutionary factors that brings about changes in the gene frequencies in a population through the action of differential fertility and mortality. Selection potential based on the differential fertility and mortality data have been computed for the major Scheduled Tribes of Rajasthan, using the methodology of Crow (1958) and Johnston and Kensinger (1971). It has been observed that irrespective of methodology, the index of total selection was the highest among Sahariyas while it was the lowest among Mina tribal group. The relative contribution of fertility to the index of total selection has been found exceeding that of mortality among Mina. The reverse appeared true among Kathodis, Damors and Garasias.
\end{abstract}

\section{INTRODUCTION}

Population components are of considerable importance not only in understanding population structure but also in measuring evolutionary dynamics. Differential fertility and mortality - the measures of fitness; are the most fundamental events of natural selection - a major process of evolutionary change in a population. Natural selection is differential viability and/or fertility according to genetic constitution and refers to genetically determined variation in Darwinian fitness (Harrison, 1990). In other words, a population is deemed fit, if it can maintain or increase its numbers from generation to generation in a given environment and natural selection is the process through which this occurs, eventually leading towards evolutionary changes. Neel (1958) has earlier pointed out that despite global mortality reductions and diminished constraints, there is a great need for studying selective factors in advanced and primitive societies, to understand the past and future trends of human population, in the rapidly changing world.

A number of theoretical treatises (Wallace, 1871; Fisher, 1930; Wright, 1938; Coon, 1955) exist on natural selection in human populations. But, Crow (1958) has devised an index that facilitates quantitative estimation of selective pressure provided the reproductive pattern of a population is known. This index I refers to the

Present Address: Dr. M.K. Bhasin, B-2 (GF), South City II, Gurgaon 122 002, Haryana, India

Telephone: 091-0124-4361430

E-mail: kre@vsnl.com total amount of selection and consists of two components - mortality $\left(\mathrm{I}_{\mathrm{m}}\right)$ and fertility $\left(\mathrm{I}_{\mathrm{f}}\right)$. That is, it measures the proportion by which fitness would increase with specific birth and death rates, if they were all selective and the heritability of fitness were complete (Crow, 1972). However, in reality, the genetic component in differential fertility and mortality is relatively small, due to the interplay of a host of environmental (physical socio-economic, cultural) and behavioural factors (Crow, 1966; Cruz-Coke et al., 1966; Matsunga, 1966). Thus, I does not represent total (net) intensity, but only its upper limit (maximum) for the potential action of natural selection intensity accordingly renamed as - 'Total index of Opportunity for Natural Selection' (Crow, 1966).

Johnston and Kensinger (1971) later modified Crow's (1958) index, by incorporating embryonic mortality. Subsequently, a substantial number of studies were undertaken. Studies in various populations of America, Europe and Africa (Spuhlar, 1963, 1976; Cavalli-Sforza and Bodmer, 1971) have suggested that the tribal populations are generally characterized by rather high fertility with less individual variation and early mortality. In them, the empirical values of I are roughly $<1$, with rare exceptions. But the people from advanced technological levels generally display higher values of I. The fertility component in them is at least two times the magnitude of the mortality component in contrast to the populations with simpler technologies.

Spuhlar $(1962,1976)$ reviewed and compared a large number of studies from all over the world and pointed out that the value of I ranged from 0.23 among Hutterites in the United States and 
Canada, to 3.69 among Peri in Bismarck Archipelago; and also that the mortality component was higher than the fertility component in 35 of the 57 populations studied.

In India too, several studies have attempted to measure the total potential of selection in various populations through differential fertility and mortality and study the effects of various factors including economic, socio-cultural, and physical environmental factors as, altitude etc., on the same (Basu 1967, 1972; Ghosh, 1970; Talukdar, 1971; Mukherjee, 1972; Reddy and Mukherjee, 1975; Chaudhari and Nag 1976; Chakravarty, 1976; Barua, 1976, 1983; Murty and Ramesh, 1978; Reddy and Ladshmanudu, 1979; Gupta, 1980; Rao and Murty, 1984; Padmanabha, 1985; Basu et al, 1988; Bhasin and Kshatriya, 1990; Suri Babu and Bhasin, 1991; Chachra Paul and Bhasin, 1998; Bhasin and Nag, 2002). It may be mentioned here that the index values reported by Ghosh (1970) and Basu (1972) estimated for the Kotas seem to be the highest among Indian populations studied so far (1.37 and 2.25, re spectively). Evidence of contribution of above mentioned factors on the selection intensity have also been reported by Sphular (1962, 1963, 1976) Cavalli-Sforza and Bodmer (1971) Tripp Reimer, (1980), Jorde and Durbize, (1986).

The description of area and people illustrates the tremendous ethnic, linguistic and cultural diversity among tribal groups of Rajasthan (Bhasin and Nag, 2007). Against this backdrop, it seems reasonable that differential fertility and mortality along with their ethno-cultural diversity may have significant impact on natural selection potential.

\section{MATERIAL AND METHODS}

The study sample was collected from five districts of Rajasthan state; and comprised of 356 (89 Sahariyas, 70 Minas, 61 Bhils, 62
Kathodis, 47 Damors, 27 Garasias) who have completed their reproductive life. The households were selected after an extensive field visit to the various districts of the state and identifying the villages predominantly inhabited by these population groups. A nuclear family ultimately was taken as the unit of the study.

The fertility and mortality data were collected using structured schedules and through genealogies. Reproductive performance data were collected by obtaining information on the serial outcome of each frequency or pregnancy histories. The collected information was also cross-checked from elderly members of the households. For details see Bhasin and Nag (2004).

The index of total selection has been computed following Crow (1958) and Johnston and Kensinger (1971). The two indices are as follows :

$$
\begin{aligned}
& \mathrm{I}_{1}=\mathrm{I}_{\mathrm{m}}+\mathrm{I}_{\mathrm{f}} / \mathrm{P}_{\mathrm{s}} ; \\
& \text { where } \mathrm{I}_{\mathrm{m}}=\mathrm{P}_{\mathrm{d}} / \mathrm{P}_{\mathrm{s}} ; \text { and If }=V_{\mathrm{f}} /(\overline{\mathrm{x}})^{2}
\end{aligned}
$$

and $\mathrm{I}_{2}=\mathrm{I}_{\mathrm{me}}+\mathrm{I}_{\mathrm{mc}} / \mathrm{P}+\mathrm{I}_{\mathrm{f}} / \mathrm{I} / \mathrm{P}_{\mathrm{b}} \mathrm{P}_{\mathrm{s}}$ (Crow, 1958)

Where $\mathrm{I}_{\mathrm{me}}=1-\mathrm{P}_{\mathrm{b}} / \mathrm{P}_{\mathrm{b}}, \mathrm{I}_{\mathrm{mc}}=\mathrm{P}_{\mathrm{d}} / \mathrm{P}_{\mathrm{s}} ; \mathrm{I}_{\mathrm{f}}=\mathrm{V}_{\mathrm{f}} /(\overline{\mathrm{X}})^{2}$; $\mathrm{P}_{\mathrm{b}}=\left(1-\mathrm{P}_{\mathrm{ed}}\right)$ (Johnston and Kensinger, 1971) $\mathrm{I}_{\mathrm{f}}=\mathrm{V}_{\mathrm{x}} /(\overline{\mathrm{x}})^{2}$, where $\mathrm{V}_{\mathrm{x}}$ and are the $(\overline{\mathrm{x}})$ variance of live births and average number of live births respectively; and

$\mathrm{I}_{\mathrm{me}}=1-\mathrm{P}_{\mathrm{b}} / \mathrm{P}_{\mathrm{b}}$ and $\mathrm{I}_{\mathrm{mc}}=1-\mathrm{P}_{\mathrm{d}} / \mathrm{P}_{\mathrm{s}}$

$\left(\mathrm{P}_{\mathrm{b}}, \mathrm{P}_{\mathrm{s}}, \mathrm{P}_{\mathrm{d}}\right.$ have been explained in Table $)$.

\section{RESULTS AND DISCUSSION}

In the present paper, the indexes of total selection based on differential fertility and mortality data (Table 1) have been computed using the methodologies of Crow (1958) [Table 2] and Johnston and Kensinger (1971) [Table 3]. In the tribal groups of Rajasthan, the mean number of live births was found the lowest among

Table 1: Demographic variables utilized for calculation of Index of Total Selection for Scheduled Tribes of Rajasthan

\begin{tabular}{lccccc}
\hline Population group & $\begin{array}{c}\text { Number of } \\
\text { mothers }\end{array}$ & $\begin{array}{c}\text { Number of } \\
\text { pregnancies }\end{array}$ & $\begin{array}{c}\text { Number of } \\
\text { live births }\end{array}$ & $\begin{array}{c}\text { Number of Mean } \\
\text { live births }(x)\end{array}$ & $\begin{array}{c}\text { Variance of live } \\
\text { births }(\text { Vx) }\end{array}$ \\
\hline Sahariyas & 89 & 533 & 516 & 5.80 & 4.845 \\
Minas & 70 & 345 & 329 & 4.70 & 2.880 \\
Bhils & 61 & 348 & 328 & 5.38 & 3.972 \\
Kathodis & 62 & 257 & 252 & 4.06 & 4.127 \\
Damors & 47 & 212 & 210 & 4.47 & 5.298 \\
Garasias & 27 & 146 & 145 & 5.37 & 10.319 \\
\hline Total & 356 & 1841 & 1780 & 5.00 & 4.986 \\
\hline
\end{tabular}




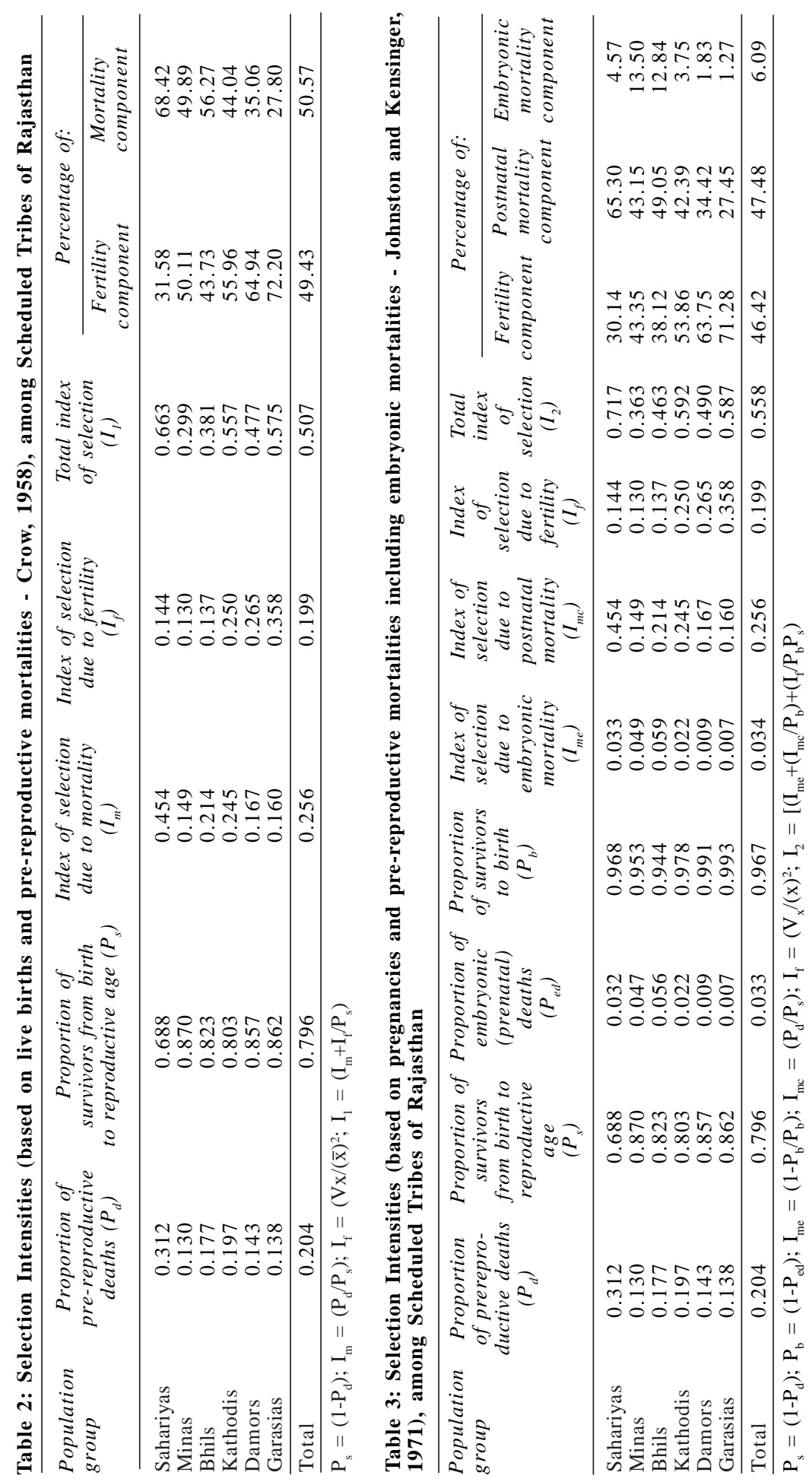


Kathodis (4.06); while it was observed the highest among Sahariyas (5.80). The mean number of live births for the pooled tribal groups worked out to 5.00.

The proportions of survivors from birth to reproductive age were observed the highest among Minas (0.870) and the lowest among Sahariyas (0.688); while other registered values within this range. Conversely, the Sahariyas showed the highest proportion of pre-reproductive deaths $(0.312)$ while the Minas recorded the lowest value (0.130). The proportion of survivors from birth to reproductive age was found 0.796 for the total population (Table 2). However, the proportions of embryonic (prenatal) deaths were observed not much different across the study population groups [range 0.007 (among Garasias) to 0.056 (among Bhils)]. Hence, the proportions of survivors to birth also fluctuated within a very narrow range of 0.944 (among Bhils) to 0.993 (among Garasias). At the aggregate level, these proportions were found 0.033 and 0.967 , respectively (Table 3 ). It has been noticed that, the index is the highest in Sahariyas; irrespective of the methodology used. However, as per Crow's formula, the index is found the lowest in Bhils, wheras as per Ru method of Johnston and Kensinger (1971), the index is the lowest in Minas. All the estimates (as per Crow's formulation), seem to be below the average value of 1.18 reported by Sphuler for various populations (1976) [the total range being 0.23 (among Hutterites) to 3.69 (among Peri of Bismarck Archipelago)]. That is, the selection pressure may be moderate among the tribal groups of Rajasthan. The index values are also lower than the indexes estimated for the Kotas by Ghosh (1970) and Basu (1972) [1.37 and 2.25 respectively].

Further, it has also been observed that the relative contribution of the fertility component exceeds the pre-reproductive mortality component among Kathodis, Damors, Garasias, while the reverse is true among Sahariyas and Bhils. Among Minas percentage contributions of the fertility and the reproductive mortality to the total index of selections were found not much different. Anumber of factors are contributing to the higher pre-reproductive mortality component, including socio-cultural and physical environmental factors. The pooled data have registered slightly higher contribution of pre reproductive mortality component than fertility component to the total index of selection (Table 2, 3).
Studies among Indian tribes indicate that prereproductive mortality contributes heavily to the process of natural selection, whereas in the population of industrially developed countries prereproductive mortality is extremely low (Spuhler, 1962; Cavalli-Sforza and Bodmer, 1971). According to this differentiation, Minas living in the developing region of Swai Madhopur in Rajasthan, may be showing a disparate trend. Even though certain socio-economic transfor-mation is noticed amongst them, as compared to others, who are residing predominantly in the more backward regions, they are not on at par with populations of developed countries. However, in India, many other populations, tribes with varying levels of development have recorded such trend, i.e. higher contribution of fertility than mortality component to the total index of selection (Ghosh, 1970; Basu, 1972; Mukherjee, 1972; Talukdar, 1971; Murthy and Ramesh, 1978; Reddy and Lakshmanudu, 1979; Bhasin and Kshatriya, 1990; Bhasin and Nag, 2002).

\section{REFERENCES}

Barua, S.: Selection intensity among the consanguineous and non-consanguineous groups of a Muslim population of 24 Parganas, West Bengal. Man in India, 56: 359 (1976).

Barua, S.: The Hajongs of Meghalaya: A bio-cultural study. Hum. Sci., 32: 190 (1983).

Basu, A.: Selection intensity in the Pahiras. Eugen. Quart., 14: 214 (1967).

Basu, A.: A demographic study of the Kota of Nilgiri Hills. J. Ind. Anthrop. Soc., 7: 29 (1972).

Basu, S.K., Kshartiya, G. and Jindal, A.: Fertility and mortality differentials among the tribal population groups of Bastar district, Madhya Pradesh, India. Hum. Biol., 60: 407 (1988).

Bhasin, M.K. and Kshatriya, G.: Fertility and mortality differentials among the different groups of Sikkim, India. J. Hum. Ecol., 1: 267 (1990).

Bhasin, M.K. and Nag, Shampa: A dermographic profile of the people of Jammu and Kashmir. 4. Selection Intensity. J. Hum. Ecol., 13: 141-146 (2002).

Bhasin, M.K. and Nag, Sampa: Demographing of the tribal groups of Rajasthan. 1. Population Structure. Anthropologist, 9(1): 1-37 (2007).

Cavalli-Sforza L. L. and Bodmer, W. F.: The Genetics of Human Populations. Freeman, San Francisco (1971).

Chachra Paul, S. and Bhasin, M.K.: Anthropodemographic study among the caste tribal groups of central Himalayas. 4. Selection intensities. J.Hum. Ecol., 9(5): 441-443 (1998).

Chakravarty. S.K.: Selection potential among Bengalee Muslims of Cachar. J. Ind. Anthrop. Soc., 11: 177 (1976). 
Chaudhari, N.R. and Kumar, R.: Demographic profile of Bhils. East. Anthrop., 29: 273-279 (1976).

Coon, C.S.: Some problems of human variability and natural selection in climate and culture. Am. Nat., 89: 257 (1955).

Crow, J.F.: Some possibilities of measuring selection intensities in man. Hum. Biol., 30: 1 (1958).

Crow, J.F.: The quality of people: Human evolutionary changes. Bioscience, 16: 863 (1966).

Crow, J.F.: Some effects of relaxed selection and mutation. Proceedings of the IVth International Congress of Human Genetics. J. DeGrouchy, E.J.G. Ebling and I. W. Henderson (Eds.). Excerpta Medica, Amesterdam (1972).

Cruz-Coke, R., Cristoffanini, A.P., Aspillaga, M. and Biancani, F.: Evolutionary forces in human populations is an envionmental gradient in Arica, Chile. Hum. Biol., 38: 421 (1966).

Fisher, R.A.: The Genetical Theory of Natural Selection. Oxford University Press, London (1930).

Garruto, R.M. and Hoff, C.J.: Genetic history and affinities . p.98. In: Man in the Andes. P.T. Baker and M.A. Little (Eds.). Dowden, Hutchinson and Ross, Stroudsburg (1976).

Ghosh, A.K.: Selection intensity in the Kota of Nilgiri Hills, Madras. Soc. Biol., 17: 224 (1970).

Gupta, R.: Selection intensity in the Sherpa. Curr. Anthrop., 21: 136 (1980).

Harrison, G.A.: Population genetics - gene frequency changes. p.208. In: An Introduction to Human Evolution, Variation, Growth, and Adaptability. G.A. Harrison, J.M. Tanner, D.R. Pilbeam and P.T. Baker. Oxford Univeristy Press, Oxford (1990).

Johnston, F.E. and Kensinger, K.M.: Fertility and mortality differentials and their implications for micro-evolutionary chage among the Casinahua. Hum. Biol., 43: 356 (1971).

Jorde, L.B. and Durbize, P.: Opportunity for natural selection in the Utah Mormons. Hum. Biol., 58: 91-114 (1986).

Matsunaga, E.: Possible genetic consequences of family planning. J. Am. Med. Assoc., 198: 533 (1966)

Mukherjee, D.P.: Some recent trends in population genetics in India. ICMR Technical Report Series, 20: 234 (1972).

Murty, J.S. and Ramesh, A.: Selection intensities among the tribal population of Adilabad District, Andhra Pradesh, India. Soc. Biol., 25: 302 (1978).
Neel, J. V.: The study of natural selection in primitive and civilized human populations. Hum. Biol., 30: 43 (1958).

Padmanabha, P.: Demographic trends of tribals. National Institute of Health and Family Welfare, New Delhi, Technical Report, 8: 93 (1985).

Rao, N.A. and Murty, J.S.: Selection intensities and inbreeding among some caste groups of Andhra Pradesh, India. Soc. Biol., 31: 114 (1984).

Reddy, P.C. and Lakhshmanudu, M.: Indices of opportunity of selection in Mala Madiga and other Indian population. J. Ind. Anthrop. Soc., 14: 245 (1979)

Reddy, P.C. and Mukherjee, D.P.: Marriage distance in two scheduled caste of Chittoor District, Andhra Pradesh. Proc. Sec. Ann. Conf. Ind. Soc. Hum. Genet., Calcutta (1975)

Spuhler, J.N.: Empirical studies of quantitative human genetics. pp. 241-257. In: Proceedings of UN/WHO Seminar on the Use of Vital Health Statistics for Genetics and Radiation Studies. United Nations, New York (1962).

Spuhler, J.N.: The scope of natural selection in man pp. 1-111. In: Genetic Selection in Man. W. J. Schull (Ed.) University of Michigan Press, Ann Arbor (1963).

Spuhler, J.N.: The maximum opportunity for natural selection in some human populations, pp. 185-226. In: Demographic Anthropology: Quantitative Approaches. E.B.W. Zubrow (Ed.). University of New Maxico Press, Albuquerque (1976).

Suri Babu K. and Bhasin, M.K.: Selection intensities among occupationaly different communities Yadavs and Kammas in Andhra Pradesh. J. Hum. Ecol., 2: 77-79 (1991).

Talukdar, S.: Selection intensity in two Bagdi groups of 24-Parganas. West Bengal. J. Ind. Anthrop. Soc., 6: 131 (1971).

Tripp-Reimor, T.: Genetic demography of an urban Greek Immigrant community. Hum. Biol., 52: 255-267 (1980)

Wallace, A.R.: The Action of Natural Selection on Man. Academic Reprints, Stanford (1871) [Republished in 1953].

Wright, S.: The distribution of gene frequencies under irreversible mutation. Proc. Nat. Acad. Sci., 24: 253 (1938). 